\title{
Intensivpasienter må kartlegges systematisk for smerter
}

Mange av intensivpasientene kan ikke uttrykke om de har vondt, eller hvor vondt de har. Smerten må derfor

kartlegges med et egnet verkt $\varnothing y$ for at de skal

få rett smertebehandling.

\section{Brita Fosser Olsen}

Intensivsykepleier og forsker

Intensiv og postoperativ avdeling, Sykehuset Østfold

Tone Rustøen

Sykepleier, seniorforsker og professor II

Avdeling for FoU, Oslo universitetssykehus, Ullevål og Medisinsk fakultet, Universitetet i

Oslo

Smerte Intensivpasienter intensivsykepleier

\section{Hovedbudskap}

Mange intensivpasienter har smerter. Sykepleierne har en sentral og viktig rolle i å kartlegge smerten systematisk og regelmessig med egnede smertekartleggingsverkt $\varnothing y$. Deretter må de gi tilpasset smertelindring basert på kartleggingen. 
Hos en intensivpasient foreligger det truende eller manifest, akutt svikt i en eller flere vitale funksjoner, og svikten antas å være helt eller delvis reversibel (1). Disse pasientene er kritisk syke, og mange av dem blir både respiratorbehandlet og sederte. Det gjør det vanskelig for dem å uttrykke hvordan de har det.

Det er forsket på hvordan intensivpasientene har det under intensivoppholdet, og mange av pasientene har plagsomme symptomer. I en studie av intensivpasienter med høy risiko for å d $\varnothing$ så man at ubehandlede og plagsomme symptomer forekom hos majoriteten av dem.

Forekomsten av symptomer varierte fra 75 prosent (tretthet) til 27 prosent (forvirring). Pasientene opplevde at tørste var moderat intenst, mens tungpustethet, redsel, forvirring og smerte var moderat plagsomt (2).

Ressurspersoner innen symptomforskning hos intensivpasienter anbefaler derfor at de fem symptomene smerte, tørste, angst, tungpustethet og søvnproblemer alltid bør kartlegges hos intensivpasienter (3).

\section{Over halvparten har smerter}

Det er vist at mer enn 50 prosent av intensivpasientene opplever smerter under intensivoppholdet, men forekomsten kan variere fra studie til studie $(4,5)$. Intensivpasienter har moderate til alvorlige smerter, både i ro og under prosedyrer.

\section{$\equiv \ll$ Mer enn 50 prosent av intensivpasientene opplever smerter under intensivoppholdet.»}

Det å snu eller mobilisere en intensivpasient er en av de mest smertefulle prosedyrene man gjør overfor pasientene (6).

I tillegg viser en internasjonal unders $\varnothing$ kelse av intensivpasienter på 192 intensivavdelinger i 28 land at det å fjerne toraksdren og sårdren og det å legge inn arteriekateter blir beskrevet som noen av de mest smertefulle prosedyrene for denne pasientgruppen (7).

Smerte er definert som en ubehagelig sensorisk og emosjonell opplevelse som følge av faktisk eller potensiell vevsødeleggelse, og den er alltid subjektiv (8). I tillegg til at smerter er ubehagelige for pasienten, kan de ha uheldige fysiologiske konsekvenser. 
Ubehandlede smerter kan være en kilde til stress $(9,10)$ og er assosiert med både $\varnothing \mathrm{kt}$ posttraumatisk stresslidelse og lavere livskvalitet (11). Akutte smerter kan også utvikle seg til å bli langvarige hvis de ikke blir adekvat behandlet (12).

I en norsk studie undersøkte Langerud og medarbeidere forekomsten av kronisk smerte hos tidligere intensivpasienter tre måneder og ett år etter utskrivelse fra intensivavdelingen.

Tre måneder etter utskrivelse hadde 49 prosent av intensivpasientene smerter, og ett år etter utskrivelse hadde 38 prosent av pasientene smerter. I denne studien hadde pasientene mest smerter i skulder og mageregionen (13).

\section{Smerten må kartlegges før behandling}

For å kunne gi rett smertebehandling til denne pasientgruppen må smerten kartlegges. På lik linje med andre sårbare pasientgrupper, som for eksempel pasienter med en demenssykdom, små barn eller de uten språk, er intensivpasienter ofte vanskelig å smertekartlegge.

Mange av pasientene kan ikke uttrykke om de har vondt, eller hvor vondt de har. Det kan skyldes selve sykdommen, eventuell respiratorbehandling, nedsatt bevissthet eller at de har utviklet delir.

\section{三 «Mange av pasientene kan ikke uttrykke om de har vondt, eller hvor vondt de har.»}

I tilfeller der helsepersonellet selv vurderer om

intensivpasientene har smerter, tyder forskning på at de har en tendens til å undervurdere smertene (14).

Selvrapportering av smerte er derfor gullstandarden i all smertekartlegging, da smerte er en subjektiv opplevelse (8).

Selv om mange intensivpasienter er kritisk syke, har de ofte mulighet til selv å rapportere om smerter, og angi hvor sterk smerten oppleves. Derfor må vi som helsepersonell spørre pasienter om de har smerter, selv om pasientene for eksempel blir respiratorbehandlet.

Hos intensivpasienter som ikke kan selvrapportere smerter, må helsepersonellet identifisere tegn på smerter. Vitale tegn som $\varnothing \mathrm{kt}$ puls, blodtrykk og respirasjonsfrekvens kan være tegn på smerter, men hos intensivpasientene er ikke slike vitale tegn pålitelige for å vurdere smerter $(15,16)$. 
Det kan være flere årsaker til dette, blant annet at intensivpasientene ofte er septiske, eller at de får legemidler som betablokkere eller vasopressor (se faktaboks), noe som påvirker puls og blodtrykk, og som medfører at vitale tegn hos en intensivpasient ikke responderer på samme måte som hos en frisk person når de blir utsatt for smerte.

Det er også påvist at forandringer i fysiologiske parametere kan forårsakes av frykt, angst og andre psykiske stressorer (16), eller at forandringene kan bli undertrykt av analgesi (17). Derfor anbefales det ikke å bruke vitale tegn alene til å kartlegge smerte (18).

\section{Vasopressor}

Vasopressor er et stoff som får blodårene til å trekke seg sammen (vasokonstriksjon), og som dermed fører til økning av blodtrykket.

Kilde: Store medisinske leksikon

\section{Andre metoder for å kartlegge smerte}

Det forskes i dag også på om man kan kartlegge smerter med mer tekniske hjelpemidler enn det å observere atferden hos denne pasientgruppen (19). En metode er å bruke pupillereaksjon hos pasienten. Metoden bygger på antakelsen om at pupillene dilaterer - utvider seg - ved smertefulle stimuli $(20,21)$.

En annen metode er å måle innholdet av svette i håndflatene, og denne metoden bygger på antakelsen om at svettekjertlene aktiveres ved smertefulle stimuli (22). Men her trengs det mer forskning før disse metodene eventuelt kan brukes i klinisk praksis til å vurdere smerter hos intensivpasientene.

Det som anbefales for å kartlegge smerte hos pasienter som ikke kan rapportere om smerter selv, er å observere pasientens atferd (18).

Med atferd menes for eksempel hvilket ansiktsuttrykk pasienten har, hvordan pasienten beveger seg (for eksempel ulike grader av armbevegelser), hvordan pasienten samarbeider med respiratoren (om pasienten tolererer eller motarbeider respiratoren), hvordan pasienten bruker stemmen (normalt toneleie eller høylytt jamring), eller hvilke ulike grader av muskelspenning pasienten har. 


\section{Smerte bør vurderes med kartleggingsverktøy}

Det anbefales å bruke pålitelige smertekartleggingsverktøy for å vurdere smerter hos intensivpasienter (18). Det finnes ulike endimensjonale verktøy som ofte anvendes dersom man vil kartlegge tilstedeværelsen og intensiteten av smerte.

Slike kartleggingsverktøy forutsetter litt evne til kommunikasjon og en viss grad av abstrakt tenkning fra pasientens side. En numerisk smerteskala (NRS) er en linje som er gradert fra o til 10, hvor pasientene skal vurdere smerten fra o (ingen smerte) til 10 (verst tenkelige smerte).

Pasienten blir bedt om enten å si et tall eller krysse av for eller peke på det tallet som best beskriver smerteintensiteten deres. Et annet endimensjonalt verktøy er en visuell analog skala (VAS), som er en rett linje hvor pasienten kan markere graden av smerte.

Resultatet kan avleses i for eksempel millimeter, hvor o $\mathrm{mm}$ betyr ingen smerte, og $100 \mathrm{~mm}$ betyr verst tenkelige smerte.

\section{Ansiktsskala kan brukes til kartlegging}

For noen pasienter vil en ansiktsskala være enklere å bruke. En ansiktsskala består av ulike ansikter med forskjellig uttrykk, fra smilefjes til gråtende og lidende ansikt. Pasienten peker på det ansiktet som best beskriver hans eller hennes smerte.

En skala med ordgrupper, som for eksempel ingen, mild, moderat og alvorlig smerte, kan også brukes, hvor pasienten da velger det ordet som best beskriver smerten. Til intensivpasienter anbefales det $\mathrm{i}$ internasjonale retningslinjer å bruke en NRS (18).

Chanques og medarbeidere (23) sammenliknet ulike kartleggingsverkt øy for denne pasientgruppen, og NRS viste best resultat ved at det var enkelt i bruk og var det verktøyet som intensivpasientene selv foretrakk. En NRS kan anvendes både på intuberte og ikke-intuberte intensivpasienter.

\section{Pasientens atferd bør observeres}

Der pasientene ikke har mulighet til å angi smerteintensitet selv, vil ikke en NRS kunne brukes. I slike situasjoner anbefales det å bruke kartleggingsverkt øy hvor sykepleieren observerer pasientenes atferd for å kartlegge pasientens smerte (18). 
Både internasjonale retningslinjer (18) og nyere analyser av tilgjengelige kartleggingsverktøy (24) anbefaler enten Behavioral Pain Scale (BPS) $(25,26)$ eller Critical-Care Pain Observation Tool (CPOT) (27). Når man kartlegger smerte med disse verktøyene, observeres pasientens atferd i ett minutt.

Deretter skåres de ulike atferdsområdene før man legger sammen delskårene til en total smerteskår, som brukes for å beskrive smerteintensiteten til pasienstene. Både BPS og CPOT er oversatt til norsk og anvendt og validert på norske intensivpasienter (28-30).

\section{Kartlegging må skje systematisk og regelmessig}

Det er viktig å kartlegge smerte hos intensivpasientene systematisk og regelmessig, noe som også vektlegges i internasjonale retningslinjer (18). I et doktorgradsprosjekt vurderte Olsen og medarbeidere intensivpasienters smerte systematisk og regelmessig med enten NRS eller BPS.

\section{$\equiv$ ¿Det er viktig å kartlegge smerte hos intensivpasientene systematisk og regelmessig.»}

I denne studien ble smertekartleggingen systematisert og gjort regelmessig ved å bruke en algoritme. Studien viste at denne måten å smertekartlegge pasientene på kunne ha betydning for både kortere respiratortid og kortere liggetid på intensivavdeling (31).

Funnene st $\varnothing$ ttes av blant annet Chanques og medarbeidere, som viser at systematisk evaluering av smerte og agitasjon er assosiert med redusert forekomst av smerte, agitasjon, respiratortid og nosokomiale infeksjoner (se faktaboks) (32).

I tillegg vil man, hvis man kartlegger smerteintensiteten regelmessig, få en unik mulighet til å evaluere i hvilke situasjoner intensivpasienter får smerter, for eksempel om det er i ro eller under mobilisering.

Man vil også kunne følge smerteintensiteten over tid ved å se på hvordan smerteintensiteten utvikler seg, og kunne evaluere effekten av smertelindrende tiltak, for eksempel ved å sammenlikne smerteintensiteten før og etter et smertelindrende tiltak. 
Hvis en pasient for eksempel kun har smerter under mobilisering og ikke i ro, kan man kanskje vurdere mer kortvirkende analgetika rett før mobilisering, men ikke mer grunnmedikasjon. Hvis en pasient for eksempel har smerter også i ro, bør man kanskje vurdere mer grunnmedikasjon.

Denne detaljkunnskapen om smertene kan altså brukes til å tilpasse og individualisere smertebehandlingen til pasientene.

\section{Nosokomial}

Nosokomiale infeksjoner betegner infeksjoner som man smittes med på sykehus eller andre helseinstitusjoner. En nosokomiell infeksjon er det samme som en sykehusinfeksjon.

Kilde: $\underline{\text { Store medisinske leksikon }}$

\section{Smertekartleggingene må dokumenteres}

Det er viktig at smertekartleggingene dokumenteres. Kun når smerteintensiteten er dokumentert, får man et godt bilde av smerten over tid. Ved å dokumentere smerteintensiteten kan man lett få et bilde av hvordan smerten er, istedenfor å måtte lete etter informasjon om smerte i annen skriftlig dokumentasjon, som det ofte er mye av.

\section{«Kun når smerteintensiteten er dokumentert, får man et godt bilde av smerten over tid.»}

Smerten bør vurderes og dokumenteres både når man forventer at pasienten har smerte, og når man ikke forventer at pasienten har smerte. Sammenliknet med for eksempel blodtrykk dokumenteres ikke kun de blodtrykksmålingene som er for lave.

Man dokumenterer også de målingene som er innenfor normalområdet for å kunne få et helhetlig bilde. Slik bør det også være med smerte. Dokumentasjon av at pasienten ikke har smerter, er like viktig som dokumentasjon av at pasienten har smerter. Det er det store bildet som er viktig, og trendene i smerteintensiteten som er interessant. 


\section{Sykepleieren er sentral i smertebehandlingen}

Sykepleieren har en sentral og viktig rolle i

smertebehandlingen av intensivpasienten. Sykepleieren er ofte til stede hos pasienten hele døgnet.

Derfor har sykepleieren en unik mulighet til å kartlegge og samle inn informasjon om smerten, blant annet om hvordan pasienten responderer på smertelindringen, og i hvilke situasjoner pasienten får smerter.

Det er legen som ordinerer de smertelindrende medikamentene, men det er ofte sykepleieren som eventuelt reduserer eller $\varnothing$ ker på medikamentene innenfor de ordinerte rammene, og som gir tilbakemelding på om smertelindringen er god nok. Vellykket smertelindring krever derfor et godt, tverrfaglig samarbeid.

Ofte trenger intensivpasientene sterke smertelindrende medikamenter, som for eksempel opioider. De siste årene har det vært en tendens til å gi multimodal smertelindring til disse pasientene (18). Det innebærer at det gis flere medikamenter som utfyller hverandre, og som angriper smerten på flere måter.

Slik behandling kan blant annet innebære ulike medikamenter og ulike administrasjonsmåter, men også ulike typer blokader og ikke-medikamentelle metoder.

\section{Også ikke-medikamentelle metoder kan brukes}

Ikke-medikamentelle metoder er ofte en tilleggsbehandling til medikamentell behandling. Mens mange av de medikamentelle metodene har mange bivirkninger, er de ikke-medikamentelle metodene ofte både billige og ufarlige.

En ny litteraturgjennomgang viste at det har blitt forsket på om både hypnose, massasje, distraksjon, avslapning, spirituell omsorg, harpemusikk, det å lytte til naturlige lyder, akupunktur og emosjonell støtte kan ha en effekt på smerter hos intensivpasienter (33).

Litteraturgjennomgangen viste at akupunktur, hypnose og det å lytte til naturlige lyder var assosiert med en reduksjon i smerteintensiteten hos intensivpasienter, og at det bør forskes mer på. 
Kanskje det blir mer vanlig å tilby alternative smertelindrende metoder i fremtiden i tillegg til multimodal medikamentell smertelindring til denne pasientgruppen?

\section{Overlevende kan få nye helseproblemer}

Mange intensivpasienter som overlever intensivoppholdet, får nye eller forverrede helseproblemer etter intensivoppholdet. Disse nye eller forverrede helseproblemene kalles med en samlebetegnelse for «Post Intensive Care Syndrom» (PICS) og innebærer både fysiske, mentale og kognitive helseproblemer (34).

Mer enn 50 prosent av tidligere intensivpasienter har et eller flere slike nye eller forverrede helseproblemer etter intensivoppholdet (35). Det er derfor viktig å arbeide for å forbedre alle leddene i intensivbehandlingen, også egen sykepleiepraksis, slik at man eventuelt kan forhindre at pasientene får plager etter intensivbehandlingen.

En enkel måte å forbedre praksis på når det gjelder smerter hos intensivpasientene, er å forbedre smertekartleggingen med systematisk bruk av pålitelige smertekartleggingsverkt $\varnothing y$ og god dokumentasjon av kartleggingen.

Ved å forbedre egen praksis kan pasientene få bedre tilpasset smertelindring gjennom intensivoppholdet og eventuelt få en bedre hverdag etter intensivoppholdet.

\section{Referanser}

1. Norsk Sykepleierforbund. Definisjoner. Oslo; 2006.

Tilgjengelig fra: https://www.nsf.no/visartikkel/125357/270500/Definisjoner (nedlastet 17.02.2020).

2. Puntillo K, Arai S, Cohen NH, Gropper MA, Neuhaus J, Paul SM, et al. Symptoms experienced by intensive care unit patients at high risk of dying. Crit Care Med.

2010;38(11):2155-60.

3. Chanques G, Nelson J, Puntillo K. Five patient symptoms that you should evaluate every day. Intensive Care Med. 2015;41(7):1347-50.

4. Alasad JA, Abu Tabar N, Ahmad MM. Patients' experience of being in intensive care units. J Crit Care. 2015;30(4):859.e711. 
5. Demir Y, Korhan EA, Eser I, Khorshid L. Factors affecting experiences of intensive care patients in Turkey: Patient outcomes in critical care setting. J Pak Med Assoc.

2013;63(7):821-5.

6. De Jong A, Molinari N, De Lattre S, Gniadek C, Carr J, Conseil $\mathrm{M}$, et al. Decreasing severe pain and serious adverse events while moving intensive care unit patients: A prospective interventional study (the NURSE-DO project). Crit Care. 2013;17(2):R74.

7. Puntillo KA, Max A, Timsit JF, Vignoud L, Chanques G, Robleda $G$, et al. Determinants of procedural pain intensity in the intensive care unit. The Europain(R) study. Am J Respir Crit Care Med. 2014;189(1):39-47.

8. International Association for the Study of Pain. IASP Terminology. 1994. Tilgjengelig fra: https://www.iasppain.org/Education/Content.aspx?ItemNumber $=1698$ (nedlastet 17.02.2020).

9. So HM, Chan DS. Perception of stressors by patients and nurses of critical care units in Hong Kong. Int J Nurs Stud. 2004;41(1):77-84.

10. Hweidi IM. Jordanian patients' perception of stressors in critical care units: a questionnaire survey. Int J Nurs Stud. 2007;44(2):227-35.

11. Schelling G, Stoll C, Haller M, Briegel J, Manert W, Hummel T, et al. Health-related quality of life and posttraumatic stress disorder in survivors of the acute respiratory distress syndrome. Crit Care Med. 1998;26(4):6519.

12. Kemp HI, Laycock H, Costello A, Brett SJ. Chronic pain in critical care survivors: a narrative review. Br J Anaesth. 2019;123(2):e372-84.

13. Langerud AK, Rustoen T, Brunborg C, Kongsgaard U, Stubhaug A. Prevalence, location, and characteristics of chronic pain in intensive care survivors. Pain Manag Nurs. 2018;19(4):366-76.

14. Lopez-Alfaro MP, Echarte-Nuin I, Fernandez-Sangil P, Moyano-Berardo BM, Goni-Viguria R. Perception of pain in post-surgical patients in intensive care units. Enferm Intensiva. 2019;30(3):99-107. 
15. Gelinas C, Johnston C. Pain assessment in the critically ill ventilated adult: validation of the Critical-Care Pain Observation Tool and physiologic indicators. The Clinical Journal of Pain. 2007;23(6):497-505.

16. Gelinas C, Chanques G, Puntillo K. In pursuit of pain: Recent advances and future directions in pain assessment in the ICU. Intensive Care Med. 2014;40(7):1009-14.

17. Jeitziner MM, Schwendimann R, Hamers JP, Rohrer O, Hantikainen V, Jakob SM. Assessment of pain in sedated and mechanically ventilated patients: An observational study. Acta Anaesthesiol Scand. 2012;56(5):645-54.

18. Devlin JW, Skrobik Y, Gelinas C, Needham DM, Slooter AJC, Pandharipande PP, et al. Clinical practice guidelines for the prevention and management of pain, agitation/sedation, delirium, immobility, and sleep disruption in adult patients in the ICU. Crit Care Med. 2018;46(9):e825-73.

19. Azevedo-Santos IF, DeSantana JM. Pain measurement techniques: Spotlight on mechanically ventilated patients. J Pain Res. 2018;11:2969-80.

20. Yang LL, Niemann CU, Larson MD. Mechanism of pupillary reflex dilation in awake volunteers and in organ donors. Anesthesiology. 2003;99(6):1281-6.

21. Lukaszewicz AC, Dereu D, Gayat E, Payen D. The relevance of pupillometry for evaluation of analgesia before noxious procedures in the intensive care unit. Anesth Analg. 2015;120(6):1297-300.

22. Storm H. Changes in skin conductance as a tool to monitor nociceptive stimulation and pain. Curr Opin Anaesthesiol. 2008;21(6):796-804.

23. Chanques G, Viel E, Constantin JM, Jung B, de Lattre S, Carr J, et al. The measurement of pain in intensive care unit: Comparison of 5 self-report intensity scales. Pain. 2010;151(3):711-21.

24. Gelinas C, Joffe AM, Szumita PM, Payen JF, Berube M, Shahiri TS, et al. A psychometric analysis update of behavioral pain assessment tools for noncommunicative, critically ill adults. AACN Adv Crit Care. 2019;30(4):365-87. 
25. Payen JF, Bru O, Bosson JL, Lagrasta A, Novel E, Deschaux I, et al. Assessing pain in critically ill sedated patients by using a behavioral pain scale. Crit Care Med.

2001;29(12):2258-63.

26. Chanques G, Payen JF, Mercier G, de Lattre S, Viel E, Jung $B$, et al. Assessing pain in non-intubated critically ill patients unable to self report: an adaptation of the Behavioral Pain Scale. Intensive Care Med. 2009;35(12):2060-7.

27. Gelinas C, Fillion L, Puntillo KA, Viens C, Fortier M. Validation of the critical-care pain observation tool in adult patients. Am J Crit Care. 2006;15(4):420-7.

28. Olsen BF, Rustoen T. Er den norske versjonen av «Behavioral Pain Scale» pålitelig og brukervennlig? Sykepleien Forskning. 2011;(03):264-72.

DOI: $\underline{10.4220 / \text { sykepleienf.2011.0168 }}$

29. Olsen BF, Rustoen T, Sandvik L, Miaskowski C, Jacobsen $\mathrm{M}$, Valeberg BT. Development of a pain management algorithm for intensive care units. Heart Lung. 2015;44(6):521-7.

30. Storsveen A, Hall-Lord M-L. CPOT - verkt øy for smertevurdering av intensivpasienter. Sykepleien Forskning. 2016;11(59668):(e-59668). DOI: $\underline{10.4220 / \text { Sykepleienf.2016.59668 }}$

31. Olsen BF, Rustoen T, Sandvik L, Jacobsen M, Valeberg BT. Results of implementing a pain management algorithm in intensive care unit patients: The impact on pain assessment, length of stay, and duration of ventilation. J Crit Care.

2016;36:207-11.

32. Chanques G, Jaber S, Barbotte E, Violet S, Sebbane M, Perrigault $\mathrm{PF}$, et al. Impact of systematic evaluation of pain and agitation in an intensive care unit. Crit Care Med. 2006;34(6):1691-9.

33. Sandvik RK, Olsen BF, Rygh LJ, Moi AL. Pain relief from non-pharmacological interventions in the intensive care unit: a scoping review. J Clin Nurs. 27.01.2020. DOI:

10.1111/jocn.15194 
34. Needham DM, Davidson J, Cohen H, Hopkins RO, Weinert

$\mathrm{C}$, Wunsch $\mathrm{H}$, et al. Improving long-term outcomes after discharge from intensive care unit: Report from a

stakeholders' conference. Crit Care Med. 2012;40(2):502-9.

35. Marra A, Pandharipande PP, Girard TD, Patel MB, Hughes

CG, Jackson JC, et al. Co-occurrence of post-intensive care syndrome problems among 406 survivors of critical illness.

Crit Care Med. 2018;46(9):1393-401. 